\title{
O FUNK OSTENTAÇÃO COMO PEDAGOGIA CULTURAL: MÚSICA, CONSUMO E A PRODUÇÃO DE SUBJETIVIDADES FEMININAS NA ESCOLA
}

\author{
Juliana Ribeiro de Vargas ${ }^{1}$ \\ Rodrigo Saballa de Carvalho ${ }^{2}$
}

\section{Resumo}

O presente artigo é decorrente de uma pesquisa que, a partir dos Estudos de Gênero e das contribuições dos estudos de Michel Foucault, tem como objetivo analisar e problematizar o modo como os discursos sobre gênero, sexualidade e consumo visibilizados por músicas filiadas ao gênero conhecido como funk ostentação têm operado na constituição de subjetividades em um grupo de jovens alunas, estudantes de uma rede pública de ensino. $\mathrm{O}$ material empírico da pesquisa decorre de observações participantes, registros em diário de campo, análise de arquivos musicais armazenados nos cartões de memória dos celulares das participantes da pesquisa e rodas de conversa realizadas com elas. As análises das músicas, bem como das rodas de conversa, evidenciam que o funk ostentação é uma importante pedagogia cultural que tem operado na produção das subjetividades femininas ao indicar determinado modo de ser mulher na contemporaneidade.

Palavras-chave: Estudos Culturais; Gênero; Discurso; Feminilidade; Subjetividade

\section{PALAVRAS INICIAIS}

Ostentação, palavra que eu gosto de ouvir Se me quer do seu lado, tem que me fazer rir Vem me buscar de Hornet, R1, RR

\footnotetext{
${ }^{1}$ Doutora em Educação pelo PPGEdu/UFRGS. Endereço: Avenida Farroupilha, 8001, Prédio 14, Sala 217, Bairro São José, CEP 92425-900, Canoas/RS, Brasil. Endereço eletrônico: jrvargas@ ulbra.edu.br

${ }^{2}$ Doutor em Educação pelo PPGEdu/UFRGS. Endereço: Av. Dom João Hoffmann, 313, no Seminário Nossa Senhora de Fátima, Erechim/RS, Brasil. Endereço eletrônico: rsaballa@ terra.com.br
} 
Me dá condição,

Deixa eu totalmente louca, chapadona de Chandon

(Mulher do Poder, MC Pocahontas)

Os versos acima descrevem a música Mulher do Poder, conhecida na voz da MC Pocahontas ${ }^{3}$. Visibilizada na programação de emissoras de rádio e também acessada através de canais da web, a referida música, assim como outras relacionadas ao estilo conhecido como funk ostentação, é escutada, cantada e compartilhada por crianças e jovens na atualidade. É interessante destacar que, na versão audiovisual, ou seja, no clipe da música divulgado pela web, a intérprete desfruta de bens de consumo de alto valor, a exemplo de acessórios de grifes famosas, como a Louis Vuitton ${ }^{4}$. Destaca ainda que, para iniciar/manter um relacionamento afetivo, seu parceiro deve, obrigatoriamente, lhe dar condição, ou seja, sustentar seus desejos e suas vaidades. Em face dessa descrição, vale questionar: estarão as jovens da atualidade, principalmente aquelas apreciadoras do estilo funk ostentação, organizando seus relacionamentos amorosos de modo semelhante à MC Pocahontas?

O presente estudo, recorte de uma investigação mais ampla, busca analisar e problematizar a constituição de subjetividades de jovens alunas contemporâneas, estudantes de uma escola de periferia, com idades entre 13 e 15 anos, frente a determinados discursos sobre gênero, sexualidade, feminilidade e consumo presentes em músicas filiadas ao gênero musical conhecido como funk ostentação e, por conseguinte, na (re)produção de formas de viver a feminilidade na atualidade. Cabe salientar que as referidas alunas escutavam e compartilhavam tais músicas através de seus aparelhos celulares, muitas vezes em meio às atividades de sala de aula, não acatando, assim, a legislação vigente, que proíbe o uso desses aparatos nas escolas da rede de ensino da qual fazem parte ${ }^{5}$. É importante destacar que um dos autores deste estudo atuava como docente na escola referida ao longo da investigação. No entanto, suas atividades profissionais restringiam-se às turmas de Anos Iniciais e desta forma, o vínculo como as alunas supracitadas constituía-se pela prática de pesquisa.

Os campos teóricos dos Estudos Culturais e dos Estudos de Gênero, em vertente pósestruturalista, e também as teorizações de Michel Foucault selecionadas para subsidiar este estudo permitem o aprofundamento da temática de análise. Em consonância com tais campos,

\footnotetext{
3 MC Pocahontas é o nome artístico de Viviane Queiroz, cantora carioca. Disponível em: http://www.brasilblogado.com/mc-pocahontas-oficial/. Acesso em: 20 jul. 2014.

${ }^{4} \mathrm{O}$ vídeo da música pode ser visibilizado pelo endereço https://www.youtube.com/watch?v=AGuf8ARymiU. Acesso em: 15 jun. 2015.

5 A escola das alunas participantes da pesquisa pertence à Rede Municipal de Ensino de Porto Alegre (RS). Tais alunas eram estudantes do último ano do Ensino Fundamental e residiam, em sua maioria, nas proximidades da escola, em comunidades de periferia urbana.
} 
compreendemos os sujeitos como constituídos e diferenciados discursivamente, segundo as condições de possibilidades de distintos contextos históricos e sociais. Logo, as jovens contemporâneas estudadas estariam sendo subjetivadas de distintos modos em suas possibilidades de vida e, dessa forma, constituiriam suas feminilidades de acordo com os diferentes discursos que as atravessam. Entendemos que os processos de constituição das subjetividades das alunas jovens estão implicados nas formas como estas vivenciam suas feminilidades na contemporaneidade, uma vez que "os modos de subjetivação, são, precisamente, as práticas de constituição dos sujeitos" (CASTRO, 2009, p. 408).

Sob a perspectiva dos Estudos Culturais, é possível compreender as manifestações significativas para os distintos grupos sociais, como as músicas escutadas pelas alunas, como pedagogias culturais e, ainda, como ações comunicativas/identitárias dos grupos sociais nos quais as jovens alunas transitam, uma vez que as referidas músicas eram compartilhadas entre elas por meio da internet e/ou pela tecnologia bluetooth. Já os Estudos de Gênero, ao deslocarem o foco de análise dos comportamentos de homens e mulheres como originários unicamente de categorizações biológicas para o entendimento destes como relacionados às construções históricas e sociais, fomenta modos diferenciados de descrição e análise desses sujeitos (LOURO, 1997). Sob essa perspectiva, gênero é compreendido como um elemento constitutivo das relações sociais baseadas nas diferenças percebidas entre os sexos (SCOTT, 1995). Em consonância com tais ideias, Teresa de Lauretis (1994) compreende gênero para além das diferenças sexuais, pois, para a autora, também estas não são universais, tampouco articuladas em razão de essências ditas únicas. Alinhada às ideias de Foucault sobre a constituição do sujeito a partir das práticas de subjetivação, a autora citada pontua a potencialidade de pensar o conceito de gênero igualmente como uma tecnologia, produto de práticas discursivas.

Com base nas conceituações de Foucault (2005), entendemos que é na circularidade que os sujeitos e as sociedades fazem das palavras que os discursos acabam por ser potencializados ou não. Como afirma sobre o tema, "o discurso não é simplesmente aquilo que traduz as lutas ou os sistemas de dominação, mas aquilo por que, pelo que se luta, o poder do qual nos queremos apoderar" (FOUCAULT, 2005, p. 10).

Vale referir que o material empírico deste estudo decorre de metodologias de investigação qualitativas de cunho etnográfico, como observações participantes e registros em diário de campo. Foram realizadas observações das jovens em diversos momentos de sua 
rotina escolar: nos espaços de recreio, em meio a algumas aulas e também nos momentos de entrada e de saída da escola. As observações sobre os comportamentos das alunas no ambiente escolar e os comentários de professores acerca dos mesmos que acabaram por atrair o olhar pesquisador para um objeto que todas as alunas utilizavam em sala de aula: os aparelhos celulares. Desta forma, apoiados as palavras de Dagmar Meyer (2012, p. 58) "de estranhar o que é entendido como normal, desnaturalizando- o e familiarizar -se com o estranho, (re)conhecendo a interdependência desses movimentos", buscamos entender melhor os modos constituídos pelas alunas para uso de tal ferramenta de comunicação.

Como já exposto, todas as jovens deste estudo faziam uso de celular próprio em diversos momentos da rotina escolar, principalmente para a audição de músicas, algumas das quais acabam por chocar, constranger a geração adulta frente ao seu conteúdo lascivo e/ou relacionado às atividades ilícitas, como é possível observar nas análises aqui apresentadas. Para conhecer melhor e problematizar o conteúdo midiático em questão, foram realizadas ainda análises dos arquivos musicais armazenados nos cartões de memória dos celulares das citadas estudantes, e alguns desses arquivos foram problematizados com as alunas em encontros de pequenos grupos, os quais denominamos rodas de conversa ${ }^{6}$. É importante destacar que as quatorze alunas foram divididas em quatro grupos, respeitando a afinidade entre elas. Foram realizados seis encontros com cada um dos grupos e em cinco dos encontros, as conversas realizadas foram gravadas em áudio e posteriormente degravadas. Apesar do planejamento prévio das temáticas de cada encontro, alguns assuntos emergiram durante os encontros, em razão de situações vivenciadas pelas alunas.

Vale destacar que o elevado número de registros musicais (mais de uma centena) e a prevalência do funk como estilo musical na maioria dos cartões de memória analisados foram aspectos que chamaram nossa atenção durante o processo investigativo. Tais mídias circulavam entre as alunas através da tecnologia bluetooth ou por programas de acesso e transferência do conteúdo da web para artefatos como computadores, celulares, aparelhos de MP3 e MP4 ${ }^{7}$. A possibilidade de ter um número elevado de músicas nos seus celulares foi destacada pelas alunas como força motivadora para o acesso/troca dessas mídias.

É possível pensar que, de modo semelhante aos chamados diários de outras épocas, os aparelhos de celular prestam-se, nos tempos atuais, ao registro de memórias/vivências das

\footnotetext{
${ }^{6}$ Em tais encontros, eram apresentadas às estudantes a letra e a versão em videoclipe, encontrada na web, de algumas músicas.

${ }^{7}$ Ares, Emule, Pirate e MP3Rocket são exemplos de programas utilizados para copiar as músicas.
} 
jovens alunas, uma vez que imagens e músicas que remetem aos amigos, aos amores e aos ídolos ficam registradas nos cartões de memória de cada aparelho. Seriam seus cartões de memória como diários digitais contemporâneos, nos quais as jovens alunas registram, constituem e são subjetivadas na sua existência. Contudo, é importante pontuar a provisoriedade e a flexibilidade que esse recurso comporta, dado que cada aluna pode possuir mais de um cartão de memória e também apagar ou registrar nele "novas memórias", como pode-se visualizar na seguinte narrativa:

\section{Ingrid: [...] É que o meu cartão de memória não quer mais entrar no meu celular. Aí eu peguei o cartão de memória do meu irmão. Eu achei lá no meio das coisas dele e peguei para mim... Aí eu peguei este aqui e vou apagar as músicas que eu não gosto. ${ }^{8}$}

Entendemos que os registros de tais alunas constituam memórias fragmentadas, distantes da ideia de totalidade e continuidade. A fim de entender melhor a constituição dessas memórias, é preciso, como afirma Bauman (2001), abandonar toda a esperança de totalidade, seja esta passada ou futura, pois elas poderiam ser descritas como "memórias fluidas".

Apresentamos a seguir considerações acerca de um ideário de feminilidade, problematizando-o por meio das perspectivas teóricas elencadas. Posteriormente, apresentamos algumas características do gênero funk ostentação, buscando visibilizar discursos sobre gênero, sexualidade e consumo evidenciados nessas músicas. Encerramos este estudo com a certeza de que outros discursos poderiam ser problematizados na procura de visibilidade para dimensões ainda pouco estudadas no que se refere à constituição juventude feminina.

\section{AMÉLIA NÃO TINHA A MENOR VAIDADE: CONSTRUÇÕES DISCURSIVAS SOBRE A FEMINILIDADE}

Amélia não tinha a menor vaidade.

Amélia é que era mulher de verdade

(Ai, que saudades da Amélia, Mario Lago e Ataulfo Alves)

\footnotetext{
${ }^{8}$ Os nomes das alunas são fictícios. Foram utilizados termos de consentimento informado, respeitando assim as questões éticas da pesquisa.
} 
Mario Lago e Ataulfo Alves apresentavam, nos anos 1940, uma mulher de verdade como aquela que apoiava seu companheiro em todas as dificuldades do cotidiano e que, ainda, não exercia a vaidade. Também a canção Marina, de Dorival Caymmi, composta na mesma década (1947), acabava por destacar a simplicidade, a ausência de vaidade como uma característica a ser apreciada nas mulheres. A mulher cantada de Caymmi não precisaria se maquiar, pois já era bonita com o que Deus lhe deu!

Autores que problematizam a história das mulheres, como Del Priore (1997), Louro (1997), Meyer (2003) e Perrot (2007), demonstram, por meio de seus estudos, que determinadas características, como o amor incondicional, a paciência constante, o recato e a simplicidade foram características estimuladas, ao longo dos tempos, nas sociedades ocidentais, a fim de naturalizar alguns comportamentos como formas adequadas para o ser mulher. Exemplo dessa afirmação pode ser percebido na associação dos comportamentos femininos à história de personagens bíblicas como Eva (a pecadora) e Maria (a submissa), as quais subsidiaram formas adequadas e inadequadas para a conduta das mulheres (DEL PRIORE, 1997).

Através dos tempos, foram constituídos discursos acerca do comportamento feminino que definem uma forma de ser mulher. É possível compreender, de acordo com as ideias de Michel Foucault (1995), que tais discursos tenham se estabelecido como regimes de verdade nas diversas sociedades. De acordo com o autor, “[...] cada sociedade tem seu regime de verdade, sua 'política geral' de verdade: isto é, os tipos de discurso que aceita e faz funcionar como verdadeiros" (FOUCAULT, 1995, p. 12).

A verdade, como afirma Foucault (1995), está centrada na forma do discurso científico, é difundida amplamente e circula nos aparelhos de educação e de informação. Pode-se pensar na potencialidade do conceito de verdade quando Foucault (1995, p. 13) afirma que, por verdade, entende "[...] o conjunto das regras segundo as quais se distingue o verdadeiro do falso e se atribui ao verdadeiro efeitos específicos de poder". Dessa forma, se determinadas características foram associadas às mulheres a partir de discursos específicos de cada sociedade, é viável inferir que estes funcionaram - e ainda funcionam - como verdades sobre as mulheres.

Vale destacar ainda que, segundo Foucault (2009), o poder, a produção da verdade (constituída através do exercício do poder) e a subjetividade são elementos relacionados no processo de condução de condutas dos indivíduos. Tal relação é tema de análise para o autor, que indaga: "[...] como se fez, numa sociedade como a nossa, que o poder não possa se 
exercer sem que a verdade se manifeste, e se manifeste na forma da subjetividade?" (FOUCAULT, 2009, p. 30). Maria Manuela Garcia (2002) corrobora o referido autor ao pontuar que as subjetividades são objetos de poder, "produtos de maquinações, de saberes e de técnicas que incluem ativamente os seres humanos num campo de visibilidade, atribuindolhes certas características e padrões de desenvolvimento" (GARCIA, 2002, p. 31). A verdade, o poder e a conduta individual dos sujeitos foram preocupações pertinentes para Foucault, e nenhum desses domínios pode ser analisado de modo isolado, como é possível observar em suas palavras: "Esses três grandes domínios da experiência só podem ser entendidos uns em relação aos outros, e não podem ser compreendidos uns sem os outros" (FOUCAULT, 2010, p. 253).

Discursos diversos permitiram que mulheres fossem queimadas na Europa em fogueiras $^{9}$ e, em outros tempos, fossem descritas como histéricas ${ }^{10}$. Foram verdades instituídas sobre as mulheres que constituíram uma proposta de educação feminina que, até o século XIX, afastava as mulheres da instrução. As mulheres deveriam ser mais educadas do que instruídas e capazes de desempenhar os papéis futuros de dona de casa, esposa e mãe (PERROT, 2007). A partir dessa premissa, configura-se como natural pensar que alunas devam ser calmas, meigas e contidas e aquelas que difiram desse perfil acabem descritas como anormais ou diferentes (WALKERDINE, 1995). Ainda sobre o mesmo tema, Marilia Pinto de Carvalho (2001) destaca que, em sua pesquisa com docentes de Anos Iniciais, as professoras relacionavam a feminilidade às características de obediência e submissão às normas. Também segundo a autora, as professoras percebiam o despertar das questões afetivo-sexuais como um empecilho para o desempenho escolar adequado das alunas, uma vez que estas, nessas condições, tornavam-se mais dispersivas. Frente a essas afirmativas, percebe-se que tanto “[...] a adesão a padrões de feminilidade mais explícitos ou acentuados tendia a ser avaliada como negativa diante do desempenho escolar das meninas, sejam esses padrões associados à submissão e ao silêncio, sejam à erotização e à sedução" (CARVALHO, 2001, p. 564).

Mesmo hoje, as posturas de alunas relacionadas a um "ideário feminino" pontuam-se por discrição, disciplina e tranquilidade, como enfatiza Lilian Santos (2007) em sua

\footnotetext{
${ }^{9}$ Referimos aqui o Malleus Maleficarium, manual escrito em 1486 utilizado pela Inquisição para descrever "feiticeiras e ao mesmo tempo dizer o que convinha pensar sobre elas" (PERROT, 2007, p. 88). É importante destacar que, em 30 anos, o referido manual foi reproduzido em 20 edições.

${ }^{10}$ Conforme coloca Perrot (2007, p. 66), “[...] a histérica é a mulher doente de seu sexo, sujeita a furores uterinos que a tornam quase louca [e que também é] objeto da clínica dos psiquiatras”.
} 
VARGAS, J. R.; CARVALHO, R. S.

dissertação de Mestrado. A referida pesquisadora buscou compreender os significados da indisciplina escolar e de suas punições na perspectiva de alunas de uma escola pública de Ensino Médio de São Paulo (SP). Segundo a autora, as moças eram mais cobradas que os rapazes para terem um comportamento "adequadamente feminino", organizado pelas características descritas anteriormente. Ao questionar um professor sobre um conflito entre alunas do noturno da escola em que realizava a pesquisa, a autora registrou o seguinte pronunciamento do docente: “[...] Os valores estão realmente mudando. Onde já se viu? Eu não esperava isso delas, isso [brigas] não é comportamento de menina" (SANTOS, 2007, p. 64).

\title{
3 ESSE É BONDE DAS MINAS QUE ANDAM NO OURO: OS DISCURSOS DO FUNK OSTENTAÇÃO
}

\author{
Bota o dedo pro alto, deixa os homens loucos \\ Esse é o bonde das minas que andam no ouro \\ Gosto de ostentar e essa é a minha vida \\ Mulher do Poder, é assim que eu sou conhecida \\ (Mulher do Poder, Mc Pocahontas)
}

Encontradas na totalidade dos cartões de memória das alunas investigadas, as músicas relacionadas ao funk são apreciadas por grande parte dos jovens (e até mesmo das crianças) nos tempos atuais. Vale destacar que mesmo aquelas alunas que afirmavam "não gostar muito" de funk tinham arquivos musicais de tal estilo, fato que corrobora as seguintes ideias: a) o grande número de arquivos armazenados era o que mais importava às alunas; b) a troca de arquivos musicais pela tecnologia bluetooth constitui-se como uma das formas de socialização entre as alunas deste estudo. Entendemos, de modo semelhante a Dayrell (2001), que o consumo cultural se tornou ferramenta importante para as trocas sociais.

A popularização do referido estilo musical é também uma dimensão a ser considerada. A forte presença do funk em nossa sociedade, em especial do estilo ostentação, pode ser percebida nas trilhas sonoras de novelas de grande audiência, na presença de artistas do gênero, a exemplo da Mc Pocahontas, em programas de televisão, bem como pelos numerosos shows que os artistas realizam mensalmente. Sobre a popularização do funk, cabe destacar as palavras do DJ Malboro, um dos percussores do estilo no Brasil:

É a verdadeira Música Popular Brasileira, a MPB, que exprime o dia-a-dia e os pensamentos das pessoas. Acho que não existe nada hoje no Brasil que tenha tanta 
força ou que seja ligado de um modo tão verdadeiro ao que as pessoas pensam como o funk. (DJ Malboro) (PLATT; NEATE, 2008, p. 85).

Segundo Dayrell (2002), o funk, assim como o rap, tem sua origem na música negra norte-americana, a qual incorporou sonoridades africanas, baseadas, segundo o referido autor, no ritmo e na tradição oral. Ressalta o autor que o funk, em sua matriz rítmica, deriva do soul norte-americano, ritmo relacionado aos movimentos civis estadunidenses e um símbolo da consciência negra daquele país.

É interessante referir as condições de emergência do gênero funk na sociedade brasileira. De um modo geral, tal ritmo musical é associado às classes sociais de menor poder aquisitivo e, por conseguinte, com uma suposta menor possibilidade de aquisição de bens de consumo. Segundo Michael Herschmann (2005), apesar de ter sido visibilizado na década de 1970 na conhecida casa de espetáculo Canecão, o funk encontrou o seu espaço posteriormente nos bairros dos subúrbios cariocas. Hoje, é possível afirmar que esse gênero é produzido/consumido por "diversos grupos e segmentos sociais, e pela indústria cultural em geral" (HERSCHMANN, 2005, p. 73) ${ }^{11}$.

As músicas relacionadas ao funk ostentação traçam, em sua maioria, narrativas acerca dos "benefícios" que o acúmulo de bens e de patrimônio proporciona aos homens jovens: a companhia de belas mulheres e a elevação de um status frente aos demais. O mesmo estilo musical apresenta músicas que descrevem os desejos femininos como unicamente relacionados à vaidade e à beleza. Nas canções, esses desejos são atendidos, de um modo geral, por homens que pagam às mulheres o que elas querem. Os relacionamentos afetivos também são organizados a partir da mesma lógica: mulheres namoram homens que "bancam" tudo o que elas desejam. Vale ressaltar que o principal meio de veiculação das músicas do funk ostentação é a web, por meio da veiculação de videoclipes das músicas dos artistas.

A música Onde eu chego eu paro tudo, interpretada pelo MC Boy do Charmes, exemplifica as afirmações anteriores. Tal música descreve que o uso de uma série de artefatos de vestuário e embelezamento de valor extremamente elevado, de marcas como Dior, Lacoste, Armani, Oakley e Hilfinger, possibilitaria aos homens encantar, seduzir e compartilhar da

\footnotetext{
11 A revista semanal Veja apresentou reportagem interessante sobre MC Guimê e sua popularização, principalmente entre os jovens de determinadas classes sociais. Disponível em: <http://veja.abril.com.br/noticia/celebridades/com-10-milhoes-de-fas-funk-e-hino-de-identidade-para-jovensbrasileiros-da-periferia>. Acesso em: 10 de Jul. 2014.
} 
companhia de belas mulheres ${ }^{12}$. O uso de adornos como cordões e correntes de ouro e, ainda, a propriedade de carros e motos de valor elevado também são destacados como ações potenciais para a elevação do status de quem os usa. A versão audiovisual (videoclipe) desta e de outras músicas semelhantes visibilizam homens jovens cercados de belas mulheres e ostentando artigos de luxo como os citados ${ }^{13}$. A seguir, apresentamos excertos da música que evidenciam as afirmações.

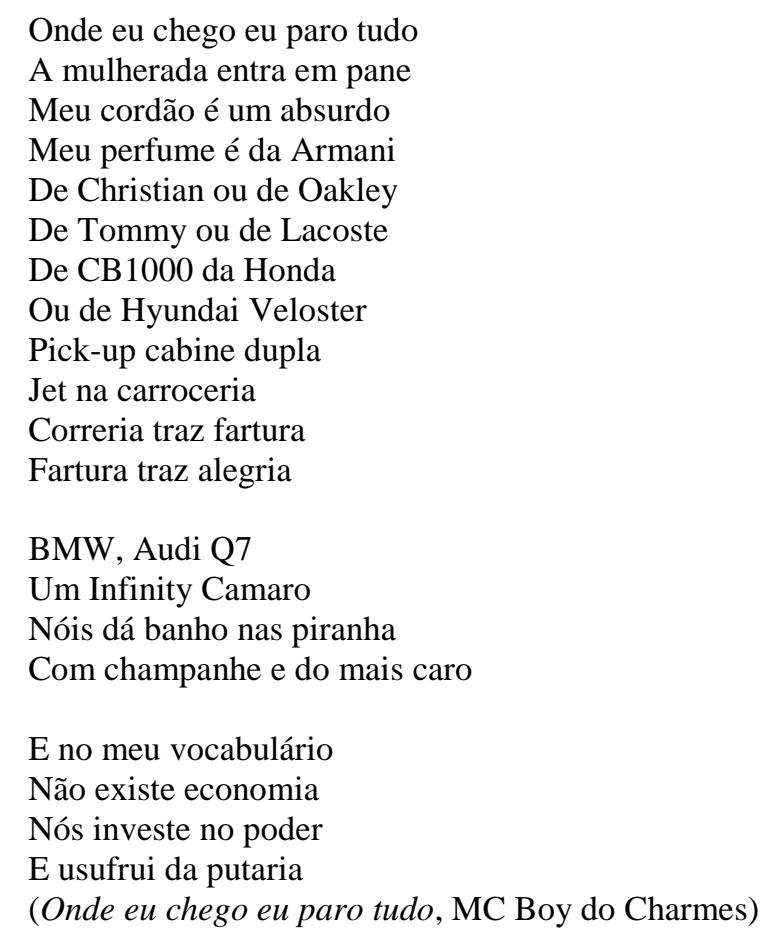

A partir de determinados versos da música Onde eu chego eu paro tudo, é possível pensar que o uso de artefatos de marcas de grife e de automóveis caros seja propiciado pela prática de atividades ilícitas, como roubos e furtos. Referimo-nos aqui, especificamente, aos versos "correria traz fartura, fortuna traz alegria" e "nós investe no poder e usufrui da putaria". No ambiente da periferia, é de conhecimento geral que "aqueles que fazem correria" são os sujeitos envolvidos em práticas ilícitas, a exemplo do tráfico de drogas e do comércio de máquinas caça-níqueis ${ }^{14}$. Também é possível ver tal relação nos versos: "É do meu malote que elas se apaixona" (Top do momento- Mc Danado) e "[...] qual mina vai querer os cara que hoje estouraram o cofre" (Eles tão tirando onda - Mc Boy do Charmes).

\footnotetext{
${ }^{12} \mathrm{MC}$ Boy do Charmes é o nome artístico de Wellington França, cantor e compositor.

${ }^{13}$ Podemos referir aqui as músicas Megane (MC Boy do Charmes), Plaque de 100 (MC Guimê), É o fluxo (MC Nego Blue) e as Minas do Camarote (MC Dedé).

${ }^{14}$ Como docentes, já ouvimos, de alguns alunos, que a razão de um afastamento momentâneo durante o período escolar é estar realizando "correrias por fora", ou seja, realizando atividades ilícitas.
} 
De modo semelhante ao exposto por essa música, o funk Rolê da Haybusa, de MC Dedé, também visibiliza a relação entre popularidade e consumo de caros artefatos de vestuário (roupas Hollister e Abercrombie \& Fitch, por exemplo), como podemos observar no seguinte recorte:

\author{
Área vip, whisky, no camarote só as top de elite \\ No baile (HAHA), nóis porta o kit \\ Tem hollister e abercrombie fitch \\ Meninas solteiras o baile é de vocês \\ Vem dançando uma de cada vez \\ (Rolê da Haybusa, MC Dedé $)^{15}$
}

Ao problematizar com as alunas a relação dos artefatos de consumo descritos em ambas as músicas e a real possibilidade financeira de serem adquiridos, elas destacaram a realização de atividades ilícitas como meio para a conquista de tais bens, como pode-se visualizar em suas falas:

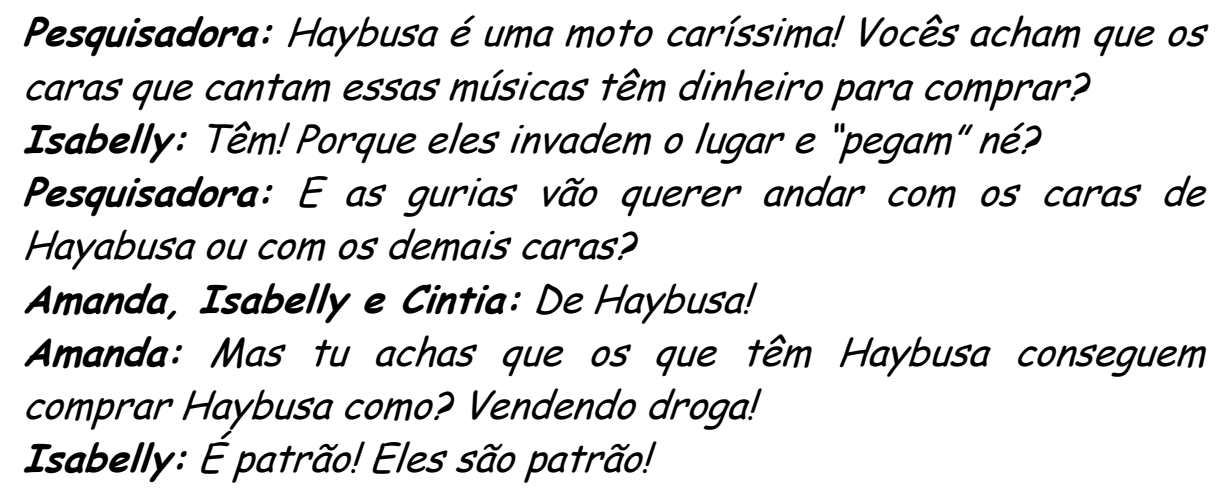

Como foi possível verificar, a música Onde eu chego eu paro tudo (MC Boy do Charmes) exemplifica essas afirmações ao associar o uso de uma série de artefatos de vestuário e embelezamento de valor extremamente elevado ao encantamento das mulheres, como nos versos " [...] a mulherada entra em pane, meu cordão é um absurdo, meu perfume é da Armani”. A mesma relação também é encontrada nos excertos abaixo:

[...] A nossa roupa é da Ed Hardy, Rio Local ou da Armani

$\mathrm{O}$ bonde tem um Audi, um Veloster e um Megane

\footnotetext{
${ }^{15}$ MC Dedé é o nome artístico de Josley Caio Faria, cantor de funk originário de São Paulo (SP). Disponível em: 〈http://vejasp.abril.com.br/materia/funk-ostentacao-paulista〉. Acesso em: 05 de Jan. 2016.
} 
Eu tô portando a Captiva com som de duzentos mil

Estilo panicat, me deu mole quando viu

(Eu sou patrão, não funcionário, MC Menor do Chapa)

[...] Cheia de tesão me olhando ela diz

Que a corrente de ouro e o tanque

Combina com a Ecko e meu Puma Disk

Chama novinha, chama

Pode chamar, vamo embora

De R1 ela gama

Um cinco estrelas ela adora.

(Ela monta na minha Rl, MC Bó de Catarina)

Expressões como "Estilo panicat, me deu mole quando viu" e "cheia de tesão" podem evidenciar o suposto interesse feminino sobre as figuras masculinas que detêm os bens destacados nas músicas: um automóvel $A u d i$, uma motocicleta $R l$ ou, simplesmente, um tênis da marca Puma Disk. O acúmulo de bens de consumo como automóveis e motocicletas de alto valor comercial também pode garantir a um homem, segundo a letra da música Pode chamar que ela vem (MC Nego Blue), a possibilidade de relacionamentos com duas mulheres: a fiel e a amante, uma vez que, ao "contar' plaquê de cem, faz-se elas 'gama"16.

É interessante destacar que os mesmos excertos apresentam, como fato comum, o interesse e a disponibilidade de uma mulher em ter até contato íntimo com um homem que ostenta os bens referidos. As frases "um cinco estrelas ela adora", "Ela monta na minha Rl", "o pitstop da noite vai ser na minha cama, a balada começa com uísque e termina em suíte", "Pode chamar que ela vem" são exemplos de nossa afirmação. Pode-se pensar que, no contexto em que são apresentadas, tais expressões podem ser compreendidas como enunciações vinculadas a enunciados que comparam o exercício da sexualidade feminina a uma relação de proveitos materiais. Ou seja, em razão dos bens que lhe são oferecidos, a mulher "escolheria" relacionar-se intimamente (ou não) com um homem. É possível ainda compreender que os mesmos enunciados se inscrevem em discursos que denotam a mulher em uma posição inferior e os homens como responsáveis pelo provimento de bens materiais, como foi destacado pelo discurso religioso por muito tempo.

Chama a atenção que a mesma relação de dependência e provimento de bens materiais é igualmente apresentada na música Mulher do Poder (MC Pocahontas), cujos versos abrem este texto. No entanto, MC Pocahontas acaba por ser descrita pelas alunas como exemplo de beleza e performance artística. Todas querem ser MC Pocahontas! É interessante destacar que

\footnotetext{
${ }^{16}$ Pode chamar que ela vem, MC Nego Blue. Disponível em: http://www.vagalume.com.br/mc-nego-blue/vempode-chamar-que-ela-vem.html>. Acesso em: 05 de Jan. 2016.
} 
o fato de um homem financiar seus desejos e vontades, como a artista descreve na música, não chega a ser entendido como um problema para as alunas. Essas ideias são visibilizadas por suas falas:

\begin{abstract}
Amanda: MC Pocahontas! Eu gosto muito! Isabelly: Ah, eu amo ela! Ela não é bagaceira, e ela é linda! Julia: Ela é linda! E eu gosto das músicas dela!
\end{abstract}

Evillyn: Porque é linda! Ela é linda e as músicas dela são legais! Eu acho ela a MC mais bonita que tem!

Pesquisadora: E por isso que tu gostas dela? Tu querias ser ela? Evillyn: Ah, eu queria! Imagina "sora"! Tirar foto lá, naqueles carrões!

A fala das alunas também reitera a relação de dependência entre homens e mulheres, naturalizando o fato de a MC Pocahontas ter todos os seus desejos atendidos pelo companheiro. Em suas palavras:

Paula: Élegal porque mostra o poder da mulher!

Pesquisadora: Que tipo de poder a música mostra?

Cintia: Ela tem dinheiro, roupas, dinheiro...

Sophia: Ela tem o poder da... Tu achas que ele deu dinheiro para ela por quê? Só porque ela deu beijinho nele? ?17 $^{17}$

Pesquisadora: Então por que ela "dá" para o cara e assim ganha tudo dele?

Paula: Não é porque ela dá, é porque ela merece! Se ele pega ela, ele tem quem ostentar!

Pesquisadora: Por que tu achas isso?

Sophia: Porque se o cara tem dinheiro ele tem que dar para ti!

Nas distintas materialidades, aqui apresentadas, é possível pensar que um enunciado como "mulher é dependente de homem" seja reiterado, apesar de filiar-se a posições de sujeito diferenciadas e a discursos distintos. Esses enunciados reverberam discursos sobre as diferenciações de possibilidades entre homens e mulheres no âmbito do exercício da sexualidade, como já apresentado. Percebe-se que essas músicas operam com base em uma mesma matriz discursiva, pautadas por características como: a) os relacionamentos afetivos

\footnotetext{
${ }^{17}$ A aluna refere-se ao órgão sexual feminino.
} 
sexuais realizam-se, unicamente, dentro da ordem heterossexual; b) é evidenciado, nas relações descritas, um protagonismo masculino como provedor material de figura feminina e esta, por sua vez, apenas é destacada pelo provimento do sexo em si.

Na contemporaneidade, através da participação em programas de TV ou ainda em outros eventos promocionais, alguns indivíduos de condição de vida simples, sem muitos recursos materiais, transformam-se em fenômenos da mídia rapidamente. E, em poucos meses, muitos acabam por usufruir de um sucesso repentino, conquistando uma melhor condição financeira que lhes possibilita a aquisição de bens de valor elevado, a exemplo dos artistas do funk ostentação. O referido estilo foi tema de um documentário, ao final do ano de 2012, bem como de reportagem de uma conhecida revista brasileira ${ }^{18}$. Embora, na visão de seus intérpretes, tais músicas retratem possibilidades de vida a serem alcançadas pela população de periferia, é válido problematizar de que modo essas possibilidades poderiam ser efetivadas.

As atitudes de consumo e a visibilidade de determinados bens e artefatos descritas, principalmente, nas músicas filiadas ao que está sendo denominado como funk ostentação parecem reiterar um discurso consumista, fundamentado em uma sociedade capitalista, a partir do qual o acúmulo de bens materiais acaba por se tornar a própria dinâmica de felicidade. Sob a premissa desse discurso, enunciados como "os ricos é que são felizes", ou ainda, "apenas o dinheiro traz felicidade" são fomentados e reproduzidos nas mídias contemporâneas. As narrativas das alunas destacam-se como enunciações sobre o referido discurso:

Paula: Essa história de dizer que dinheiro não traz felicidade eu acho a maior mentira. Pois se ele não traz felicidade, pelo menos manda trazer! Essa vida de pobre não é feliz! Eu queria é ter essa vida das músicas. Ser pobre sem glamour não tem graça nenhuma.

É possível pensar que as músicas alinhadas com o funk ostentação visibilizem a ideia de Zigmund Bauman (2005) de que, na contemporaneidade, o mundo se configura como um palco de performances, no (e do) qual somos consumidores de bens de consumo, de bens culturais e até mesmo de relacionamentos. Como afirma Bauman, as sociedades contemporâneas padecem da síndrome consumista, na qual os desejos e anseios pelos bens

\footnotetext{
18 Produzido por Renato Barreiros e Konrad Dantas. Disponível em: 〈http://www.youtube.com/watch?v=5V3ZK6jAuNI >. Acesso em: 15 de Jun. 2014.
} 
materiais devem ser atendidos de forma quase imediata. Nas palavras do autor, tal síndrome envolve a “[...] enfática negação da virtude da procrastinação e da possível vantagem de se retardar a satisfação [...]. [...] encurta radicalmente a expectativa de vida do desejo e a distância temporal entre este e a sua satisfação, assim como entre a satisfação e o depósito de lixo" (BAUMAN, 2008, p. 111). Também as palavras de Dayrell (2002, p. 124) são profícuas para a problematização quando afirma que:

\begin{abstract}
Vivemos no Brasil uma situação paradoxal. Nas últimas décadas vem ocorrendo uma modernização cultural, consolidando uma sociedade de consumo, ampliando o mercado de bens materiais e simbólicos, mas que não é acompanhada de uma modernização social. Assim, os jovens pobres inserem-se, mesmo que de forma restrita e desigual, em circuitos de informações, por meio dos diferentes veículos da mídia, e sofrem o apelo da cultura de consumo, estimulando sonhos e fantasias, além dos mais variados modelos e valores de humanidade.
\end{abstract}

Vale pontuar que algumas das músicas que reiteram enunciados e enunciações relacionadas ao discurso consumista também destacam a dimensão da beleza de modo diferenciado entre homens e mulheres. Assim, enquanto as mulheres bonitas são aquelas destacadas na referidas músicas pelos seus atributos físicos, os homens ditos bonitos, interessantes e sedutores são aqueles que se valem das roupas e dos adornos de luxo.

Estarão, nossas escolas, abordando as dimensões aqui referidas, em especial as que tangem as questões de gênero e consumo, na constituição de suas práticas pedagógicas?

\title{
4 É PRECISO ESCUTAR (MAIS): À GUISA DE CONCLUSÃO
}

[...] eu acho que discursos, na verdade, habitam corpos. Eles se acomodam em corpos; os corpos na verdade carregam discursos como parte de seu próprio sangue (BUTLER, 2002, p. 163)

As palavras de Butler (2002) são profícuas para pensar como os diferentes discursos, a exemplo daqueles elencados neste estudo, acabam por constituir distintos modos de ser uma jovem aluna na contemporaneidade. O próprio conceito de juventude remete à ideia de categoria plural, fato que a afasta de um modo único para descrevê-la e contextualizá-la (GARBIN, 2009; DAYRELL, 2007). Contudo, na atualidade, certas características, como 
beleza, espontaneidade, vitalidade e versatilidade, acabam por ser naturalmente associadas à condição juvenil, exaltadas por diversos discursos circulantes em nossa sociedade, a exemplo do discurso midiático e do discurso médico.

Destacamos ainda o armazenamento de arquivos musicais nos cartões de memória das jovens alunas como um enredo polifônico, tal como afirma Fischer (2001). Nesse enredo, estão inseridas "vozes", como as de amigos e colegas com os quais as estudantes compartilhavam os arquivos musicais, como também a própria voz da mídia, que descreve seus ídolos, os personagens sociais apreciados pela juventude, vozes essas que corroboram diferentes discursos, os quais acabam por constituir distintos modos de ser uma jovem aluna na contemporaneidade.

A respeito da produtividade das diversificadas mídias na constituição dos sujeitos, Rosa Fischer (2001, p. 588) afirma: “[...] a mídia não apenas veicula, mas também constrói discursos e produz significados, identidades e sujeitos [...]". Vale pontuar que, segundo a referida autora, as feminilidades acabam por ser "reforçadas, imaginadas, dinamizadas, polemizadas, enfim, construídas na cultura" (FISCHER, 2001, p. 591). Hoje, as várias formas de veiculação da mídia fazem-se presentes no cotidiano da maioria da população, visto, por exemplo, o número crescente de usuários de internet. Assim, as diversas formas da mídia "tornam-se cada vez mais essenciais em nossas experiências contemporâneas, e assumem características de produção, veiculação, consumo e usos específicos em cada lugar do mundo" (FISCHER, 2007, p. 293). Logo, é possível pensar que a mídia fomente a visibilidade de estilos e gostos, bem como de histórias de vida, ações essas que contribuem para a constituição e assimilação de discursos diversos pela sociedade. Sobre o tema, Rosa Fischer (2002, p. 86) afirma:

[...] poderia dizer-se que a mídia se constitui um espaço de "visibilidade de visibilidades"; ela e suas práticas de produção e circulação de produtos culturais constituiriam uma espécie de reduplicação das visibilidades de nosso tempo. Da mesma forma, poderíamos dizer que a mídia se faz um espaço de reduplicação dos discursos, dos enunciados de uma época. Mais do que inventar ou produzir um discurso, a mídia reduplicá-lo-ia, porém, sempre a seu modo, na sua linguagem, na sua forma de tratar aquilo que "deve" ser visto ou ouvido.

Fabiana Marcello (2005) também considera a mídia como um espaço que produz, por meio da ação das linhas de subjetivação, formas de reconhecimento dos sujeitos pela aproximação e semelhança de seus comportamentos e posturas àqueles considerados como exemplo de normatividade. De acordo com pesquisas já realizadas, os enunciados veiculados 
pela mídia acabam por constituir a subjetividade de meninas e jovens (FISCHER, 2002). Tais enunciados fomentam, por exemplo, a ligação entre o discurso biológico e o discurso da feminilidade. Sendo assim, muitas das características do "ser mulher" são descritas a partir da Biologia, como exemplifica a autora (FISCHER, 2001, p. 595):

[...] a feminilidade seria "dada" por um conjunto de características originadas da condição biológica, como a do 'mistério feminino' (relacionado basicamente à possibilidade de ser mãe), ao mesmo tempo que por uma "necessária" disponibilidade dos corpos da menina e da mulher a se sujeitarem a técnicas disciplinares, cuidados e tratamentos, indispensáveis à conquista amorosa; [...]

No entanto, nos dias atuais, é preciso considerar que os enunciados sobre a feminilidade subjetivem as jovens a buscarem relacionamentos afetivos nos quais sejam providas financeiramente e possam desfrutar do "luxo e da ostentação", a exemplo da MC Pocahontas.

A dimensão cultural também é destacada por Dayrell (2007) como espaço de constituição das identidades juvenis, através das práticas, dos símbolos e dos rituais compartilhados entre os pares e, muitas vezes, visibilizados nos próprios corpos dos jovens, a exemplo das tatuagens e piercings que ostentam. Para Dayrell (2007), essa dimensão acaba por determinar, ao menos em parte, as possibilidades para a constituição de uma condição juvenil. Dessa forma, é possível pensar que os jovens de camadas populares, como as alunas jovens deste estudo, enfrentam:

[...] desafios consideráveis. Ao lado da sua condição como jovens, alia-se a da pobreza, numa dupla condição que interfere diretamente na trajetória de vida e nas possibilidades e sentidos que assumem a vivência juvenil. Um grande desafio cotidiano é a garantia da própria sobrevivência, numa tensão constante entre a busca de gratificação imediata e um possível projeto de futuro (DAYRELL, 2007, p. 18).

Ações como trocar mensagens, conversar com colegas, realizar os exercícios de determinada disciplina e ainda ouvir música no celular pelo fone de ouvido (burlando muitas vezes o olhar do professor) tornaram-se atividades características e comumente praticadas pelos estudantes dos tempos atuais. Hoje os jovens alunos conseguem comunicar-se de diversificadas formas, sob diferentes tecnologias, em uma velocidade ímpar (GARBIN, 2009). Também é importante destacar que o estudo das produções culturais produzidas/consumidas pelo meio das periferias urbanas, a exemplo das músicas associadas ao funk ostentação, se apresenta como um caminho profícuo para a análise das práticas sociais 
VARGAS, J. R.; CARVALHO, R. S.

vividas pelos moradores que nelas habitam e também para a compreensão dos discursos circulantes em tais espaços (MOREIRA; SILVA JUNIOR, 2010). Sobre o tema, colaboram igualmente Helen Ferreira e Mauro José Costa (2010, p. 199):

A periferia não se situa mais como margem: tomou a produção de si mesma fazendo parte da cultura urbana; tem suas representações e cria visibilidade por meio de suas singularidades. Ela dita moda, faz arte, cria estilo, ameaça, incomoda, quebra barreiras, exige espaço, inventa uma cultura própria (local) [...]

Dessa forma, compreendemos como necessário continuar o estudo e a problematização acerca das formas que os discursos visibilizados pelas músicas escutadas por alunas produzem modos de viver a feminilidade na atualidade, pois visibilizar e problematizar os modos de ser e de viver das alunas jovens hoje é possibilitar uma melhor compreensão das condições que organizam a constituição das culturas juvenis femininas. Certamente, muitos outros discursos poderiam ser aqui problematizados, não em busca de soluções mágicas e imediatas, mas sim na busca de visibilidade para dimensões ainda pouco estudadas no que se refere à juventude feminina.

FUNK OSTENTAÇÃOAS A CULTURAL PEDAGOGY: MUSIC, CONSUMPTION AND THE PRODUCTION OF FEMALE SUBJECTIVITIES IN SCHOOL

\begin{abstract}
This article is the result of a research that, based on the Gender Studies and the contributions of Michel Foucault's studies, aims to analyze and discuss how discourses on gender, sexuality and consumption made visible by music of the genre known, in Brazil, as funk ostentação have operated in the constitution of subjectivities in a group of young female students of a public school system. The empirical material comes from participant observations, records in a field diary, analysis of music files stored on memory cards of mobile phones of the survey participants and conversation circles carried out with them. Analyses of the songs as well as of the conversation circles show that funk ostentação is an important cultural pedagogy that has been operating in the production of female subjectivities when it indicates a certain way of being a woman nowadays.
\end{abstract}


Keywords: Cultural Studies; Genre; Discourse; Femininity; Subjectivity

\section{EL FUNK OSTENTAÇÃO COMO PEDAGOGIA CULTURAL: MUSICA, CONSUMO Y LA PRODUCIÓN DE SUBJETIVIDADES FEMININAS EN LA ESCUELA}

\section{Resumen}

El presente estudio es resultado de una investigación que, a partir de los Estudios de Género y de los aportes de los Estudios de Michel Foucault, tiene como objetivo analizar y problematizar de qué modo discursos sobre género, sexualidad y consumo, presentes (y visibilizados) en canciones pertenecientes al género conocido, en Brasil, como funk ostentação han operado en la constitución de subjetividades en un grupo de jóvenes alumnas, estudiantes de una red pública de enseñanza. El material empírico de la investigación proviene de observaciones participantes, registros en un diario de campo, análisis de archivos musicales almacenados en las tarjetas de memoria de los celulares de las participantes de la investigación y de ruedas de charla realizadas con ellas. Los análisis de las canciones, así como los de las ruedas de charla realizadas con las alumnas ponen de manifiesto que el funk ostentação constituye una importante pedagogía cultural que ha operado en la producción de las subjetividades femeninas al indicar un determinado modo de ser mujer en la contemporaneidad.

Palabras clave: Estudios Culturales; Género; Discurso; Feminidad; Subjetividad

\section{REFERÊNCIAS}

BAUMAN, Zygmunt. Modernidade líquida. Tradução: Plínio Dentzien Rio de Janeiro: Jorge Zahar, 2001.

.Vida líquida. Tradução: Carlos Alberto Medeiros. Rio de Janeiro: Jorge Zahar, 2005.

.Vida para o consumo. Tradução: Carlos Alberto Medeiros. Rio de Janeiro: Jorge

Zahar, 2008. 
BUTLER, Judith. Como os corpos se tornam matéria. Revista Estudos Feministas, Florianópolis, v. 10, n. 1, p. 155-167, 2002.

CARVALHO, Marília Pinto de. Mau aluno, boa aluna? Como as professoras avaliam meninos e meninas. Revista Estudos Feministas, Florianópolis, v. 9, n. 2, p. 554-574, dez. 2001.

CASTRO, Edgardo. Vocabulário de Foucault: um percurso pelos seus temas, conceitos e autores. Belo Horizonte: Autêntica Editora, 2009.

DAYRELL, Juarez. A escola "faz" as juventudes? reflexões em torno da socialização juvenil. Educação e Sociedade, Campinas, v. 28, n. 100 - Especial, p. 1105-1128, out. 2007.

. A música entra em cena: o funk e o rap na socialização da juventude em Belo Horizonte. 2001. 409 f. Tese (Doutorado em Educação) - Faculdade de Educação da Universidade São Paulo, São Paulo, 2001.

. O rap e o funk na socialização da juventude. Educação e Pesquisa, v. 28, n. 1, p. $\overline{117-136}$, jun. 2002.

DEL PRIORE, Mary. História das mulheres no Brasil. 9. ed. São Paulo: Contexto, 1997.

FERREIRA, Helen Pereira; COSTA, Mauro José Sá Rego. Do local ao global: o serviço de radiodifusão comunitária e sua inserção no ciberespaço. In: SOBREIRA, Henrique Garcia (Org.). Educação, culturas e comunicação nas periferias urbanas. Rio de Janeiro: Lamparina, 2010. p. 197-210.

FISCHER, Rosa Maria Bueno. Mídia e educação da mulher: sobre modos de enunciar o feminino na TV. Revista Estudos Feministas, Florianópolis, v. 9, n. 2, p. 586-599, 2001/2.

Mídia, máquinas de imagens e práticas pedagógicas. Revista Brasileira de Educação, Rio de Janeiro, v. 12, n. 35, p. 290-299, maio/ago. 2007.

. Problematizações sobre o exercício de ver: mídia e pesquisa em Educação. Revista Brasileira de Educação, Rio de Janeiro, v. 20, p. 83-94, 2002.

FOUCAULT, Michel. A ordem do discurso. 12. ed. Tradução: Laura Fraga de Almeida Sampaio. São Paulo: Edições Loyola, 2005.

História da sexualidade II: o uso dos prazeres. 13. ed. São Paulo: Graal, 2009.

. O Retorno da Moral. In: FOUCAULT, Michel. Ditos e Escritos V: Ética,

Sexualidade e Política. 2. ed. Rio de Janeiro: Forense Universitária, 2010. p. 252-263.

GARBIN, Elisabete M. Conectados por um fio: alguns apontamentos sobre internet, culturas juvenis contemporâneas e escola. In: BRASIL. Ministério da Educação. Secretaria de Educação a Distância. Juventude e escolarização: os sentidos do Ensino Médio. Brasília: TV Escola, 2009. Coleção Salto para o Futuro, Ano XIX, Boletim 18. p. 30-40. 
GARCIA, Maria Manuela Alves. Pedagogias críticas e subjetivação: uma perspectiva foucaultiana. Petrópolis: Vozes, 2002.

HERSCHMANN, Micael. O funk e o hip-hop invadem a cena. Rio de Janeiro: Editora UFRJ, 2000.

LAURETIS, Teresa de. A Tecnologia do Gênero. Tradução: Suzana Funck. In: HOLLANDA, Heloisa Buarque de (Org.). Tendências e Impasses: o feminismo como crítica da cultura. Rio de Janeiro: Rocco, 1994. p. 206-242.

LOURO, Guacira. Gênero, sexualidade e educação: uma perspectiva pós-estruturalista. Petrópolis: Vozes, 1997.

MARCELLO, Fabiana de Amorim. Enunciar-se, organizar-se, controlar-se: modos de subjetivação feminina no dispositivo da maternidade. Revista Brasileira de Educação, Rio de Janeiro, v. 29, p. 139-151, 2005.

MEYER, Dagmar Elisabeth Estermann. Gênero e educação: teoria e política. In: LOURO, Guacira; NECKEL, Jane Felipe; GOELLNER, Silvana Vilodre (Orgs.). Corpo, gênero e sexualidade: um debate contemporâneo na educação. Petrópolis: Vozes, 2003. p. 9- 27.

. e PARAÍSO, Marlucy. Metodologias de pesquisa pós-críticas ou Sobre como fazemos nossas investigações. In: MEYER, Dagmar Estermann; PARAÍSO, Marlucy Alves (Orgs.). Metodologias de pesquisa pós-críticas em educação. Belo Horizonte: Mazza Edições, 2012. p.15-22.

MOREIRA, A. F. B.; SILVA JUNIOR, P. M.. Periferias, sexualidades e educação para a sexualidade: desafios para as práticas curriculares. In: SOBREIRA, Henrique Garcia (Org.). Educação, culturas e comunicação nas periferias urbanas. Rio de Janeiro: Lamparina, 2010. p. 21-40.

PERROT, Michele. Minha história das mulheres. São Paulo: Contexto, 2007.

PLATT, D.; NEATE, P.. Cultura é nossa arma: AfroReggae nas favelas do Rio. Rio de Janeiro: Civilização Brasileira, 2008.

SANTOS, Lilian Piorkowsky. Garotas indisciplinadas em uma escola de ensino médio: um estudo sob o enfoque de gênero. 2007. 193 f. Dissertação (Mestrado em Educação) Programa de Pós-Graduação em Educação, Faculdade de Educação, Universidade de São Paulo, São Paulo, 2007.

SCOTT, Joan. Gênero: uma categoria útil de análise histórica de Joan Scott. Educação \& Realidade, Porto Alegre, v. 20, n. 2, p. 71-99, jul./dez.1995. 
VARGAS, J. R.; CARVALHO, R. S.

WALKERDINE, Valerie. O raciocínio em tempos pós-modernos. Educação e Realidade, v. 2, n. 2, p. 207-233, jul./dez. 1995.

Data de recebimento: 30/01/2016

Data de aceite: 08/03/2016 